\title{
Um instrumento alternativo ao estudo de pilhas recarregáveis via Arduino+*
}

\section{Luis Carlos Mathias $^{1}$}

Departamento de Engenharia Elétrica - Universidade de Londrina

Paulo Rogério Catarini da Silva ${ }^{2}$

Osmar Henrique Moura da Silva ${ }^{3}$

Departamento de Física - Universidade de Londrina

Londrina - PR

\section{Resumo}

Recentes tecnologias tendem a invadir as escolas desencadeando modos diferenciados de se instruir conceitos científicos. Neste sentido, o presente trabalho emprega o dispositivo Arduino em uma inovadora montagem de um analisador de pilhas recarregáveis, que possibilita também uma proveitosa instrução dos conceitos físico-químicos envolvidos. Este analisador realiza a carga e descarga de pilhas, viabilizando o cálculo da sua capacidade de carga e do seu estado de saúde, cujas reflexões então fornecidas subsidiam o educador interessado. Os resultados obtidos em uma avaliação exemplar de três pilhas com diferentes capacidades de carga foram corroborados por um equipamento de laboratório de pesquisa em pilhas e baterias.

Palavras-chave: Arduino; Carregador e analisador de pilhas (recarregáveis); Escolas.

\footnotetext{
${ }^{+}$An alternative tool for the study of rechargeable batteries via Arduino

* Recebido: julho de 2016.

Aceito: novembro de 2016.

${ }^{1}$ E-mail: luis.mathias@uel.br

2 E-mail: prcsilva@uel.br

3 E-mail: osmarh@uel.br
} 


\begin{abstract}
Recent technologies tend to invade schools triggering different ways of instructing scientific concepts. Therefore, this work used the Arduino device in an innovative rechargeable batteries analyzer assem15-bly, which also provides a fruitful instruction of the physical-chemical concepts involved. This analyzer realizes batteries charges and discharges, calculating their charge capacity and health state, and the reflections subsidize the interested educator. A cells and batteries research laboratory corroborated the results obtained from an exemplary evaluation of three batteries with different charge capacities.
\end{abstract}

Keywords: Arduino; (Rechargeable) Batteries charger and analyzer; Schools.

\title{
I. Introdução
}

As pilhas e baterias recarregáveis estão presentes na grande maioria dos aparelhos eletrônicos portáteis do nosso dia-a-dia. Cada vez mais, além da durabilidade, exige-se desse tipo de componente uma maior densidade e maior capacidade de fornecimento de energia, respeitando as dimensões então padronizadas. Decorre, entretanto, de modo natural ao longo do uso destes dispositivos, uma degradação das suas propriedades físico-químicas, diminuindo consideravelmente suas eficiências, o que torna adequado o emprego de um instrumento de avaliação das reais condições deste requisitado componente eletroquímico.

Há disponível no comércio uma variedade de modelos residenciais de carregadores e analisadores de pilhas e baterias recarregáveis que, entre os mais sofisticados, permitem avaliar a capacidade de carga das mesmas. Cabendo citar um exemplar desse tipo ${ }^{4}$, detalhes como informações de corrente aplicada na pilha, capacidade de carga obtida, tempo transcorrido e tensão da pilha são diretamente fornecidos no visor do instrumento. Aliás, conectando um smartphone via bluetooth a ele, ainda se pode adquirir valores de temperatura e um gráfico da tensão da pilha em função do tempo. Todavia, o exemplar citado, constituindo-se uma das versões mais baratas, tem o valor orçado próximo de 300 reais.

Considerando isso e o crescente número de propostas em educação científica que empregam o moderno dispositivo Arduino em distintas situações ${ }^{5}$, popularizando-o no ambiente escolar, este trabalho objetiva desenvolver uma inovadora e simples proposta de montagem de um analisador de pilhas e baterias recarregáveis, de custo reduzido, que pode ser proveitosa à instrução de conceitos científicos envolvidos. Nesse sentido, é válido dizer àquele educador

\footnotetext{
${ }^{4}$ Comercializado pela marca SKYRC, modelo NC2500 (SK-100059-01).

5 Rosa et al. (2016); Silva e Mathias (2015); Cavalcante et al. (2014); Rocha et al. (2014); Souza et al. (2011); Cavalcante et al. (2011).
} 
interessado, já familiarizado ou não com o Arduino, que a presente alternativa não supera o custo de 30 reais $^{6}$, conforme recente pesquisa de preço. Também se contribui para a realização de um modelo de avaliação de três pilhas com diferentes capacidades de carga, tendo-se os resultados detalhados corroborados por um sofisticado equipamento ${ }^{7}$ de laboratório de pesquisa cujas reflexões intencionam subsidiar o educador.

\section{Teoria da análise de baterias}

Além do formato físico e da tensão nominal fornecida, um parâmetro importante das pilhas e das baterias recarregáveis é a sua capacidade de carga, cuja unidade, geralmente, é dada em miliampère hora (mAh). Neste estudo, as análises se atentarão às pilhas recarregáveis de níquel metal hidreto (NiMH) do tipo AAA de 1,5 V, escolhidas por equiparem diversos eletrônicos como brinquedos, controles remotos, calculadoras etc. Tais pilhas são compostas basicamente por um eletrodo de oxidróxido de níquel $(\mathrm{NiOOH})$, um eletrodo de uma liga metálica, geralmente lantânio níquel (LaNi5), que armazena hidrogênio, e um eletrólito composto por uma solução aquosa de hidróxido de potássio $(\mathrm{KOH})$. A reação global, expressão 1 a seguir, mostra que os hidrogênios que se encontram na liga metálica "vão" para o eletrodo de oxidró$x_{\text {xido de níquel }}^{8}$, no qual se forma o hidróxido de níquel com o elétron que balanceia a carga da reação global passando pelo circuito externo e realizando o trabalho elétrico no dispositivo em que a pilha está empregada.

$$
\mathrm{MH}+\mathrm{NiOOH} \quad \stackrel{\text { descarregamento }}{\stackrel{\text { carregamento }}{\longrightarrow}} \mathrm{M}+\mathrm{Ni}(\mathrm{OH})_{2}
$$

Mais precisamente, a reação fornece uma diferença de potencial de 1,35 V (LINDEN; REDDY, 2002). Quanto ao processo de carregamento da pilha/bateria, ele se dá através da mesma reação, mas no sentido contrário, a partir de um carregador que aplica uma diferença de potencial para tal. Como um subsídio educacional, esquematizam-se na Fig. 1 as reações envolvidas tanto no carregamento, em linha preta, como no descarregamento, em linha vermelha, inclusive aquelas com o eletrólito.

\footnotetext{
6 Inclusos o Arduino Nano e o sensor de temperatura, com valores próximos de 15 reais e 7 reais respectivamente (<http://www.dx.com/pt/p/nano-v3-0-atmega328p-development-board-for-arduino-blue-396797?tc=BRL\&gclid =CPDz1PyCqswCFQ0EkQod4VsF1A\#.Vx4s2fkrJdg>) (<http://www.baudaeletronica. com.br/sensor-de-temperatura-lm35.html>), mais a frente especificados.

${ }^{7}$ Um potenciostato/galvanostato da marca Arbin Instruments, modelo MSTAT 8000/BT2000.

8 Ou seja, há uma deintercalação de íons $\mathrm{H}^{+}$do eletrodo de lantânio níquel para o eletrólito e, na outra interface, no outro eletrodo, íons $\mathrm{H}^{+}$do eletrólito são intercalados no eletrodo de oxidróxido de $\mathrm{Ni}$.
} 


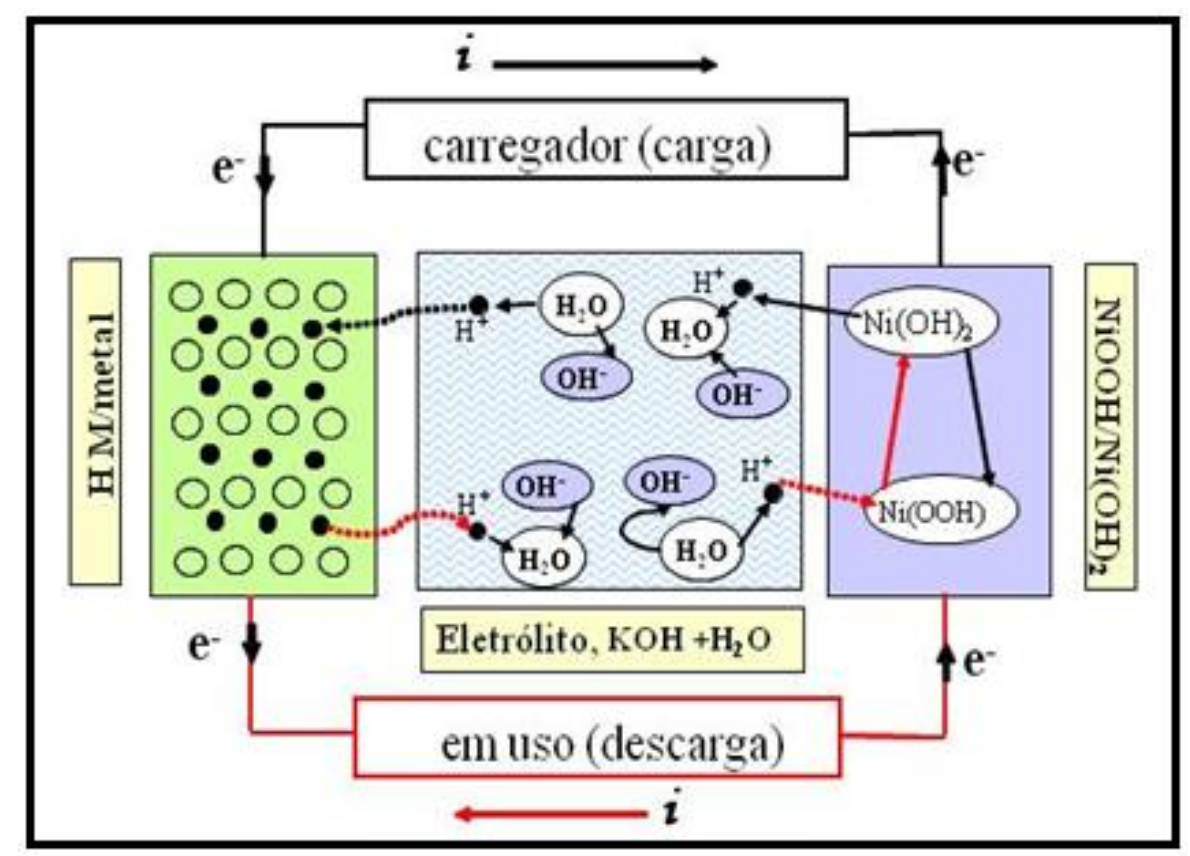

Fig. 1 - Reações envolvidas no carregamento e descarregamento. Fonte: Adaptação do esquema divulgado em Floriano (2009).

Como mostrado na Fig. 1, quando a pilha está em uso, há uma corrente elétrica passando no circuito externo e há a deintercalação de íons $\mathrm{H}+$ do hidreto metálico que reagem com a hidroxila do eletrólito formando água. Já na outra interface, a água é decomposta e o íon H+ se intercala no oxidróxido de níquel ao mesmo tempo que um elétron, que passou no circuito externo, penetra na estrutura eletrônica do oxidróxido de níquel.

No processo de carregamento de pilhas/baterias de NiMH sempre há uma elevação da temperatura, já que as reações de carga são exotérmicas. A Fig. 2 apresenta as curvas típicas de voltagem e de temperatura de baterias de NiMH em função da carga inserida em percentagem da sua capacidade de carga (ibid.).

Um fenômeno característico desse material, após determinado o tempo de carregamento, é a diminuição da voltagem da pilha/bateria, "pico", que indica que a pilha ou bateria está carregada. Na Fig. 2 este "pico" está em cerca de 120 \% da sua capacidade de carga típica, cujo valor não é real, sendo que nesta Fig. 1 se considera apenas a corrente aplicada e o tempo transcorrido, mas não qual reação acontece no interior da pilha/bateria. Isto, porque, ao mesmo tempo em que ocorre o processo de inserção e retirada de hidrogênio nos eletrodos, outras reações podem ocorrer, por exemplo, e como já esperada, a reação de recombinação do oxigênio, conforme as expressões 2 e 3 a seguir, que implicam no aumentar da temperatura da pilha e diminuição de sua voltagem.

$$
2 \mathrm{OH}^{-} \rightarrow \mathrm{H}_{2} \mathrm{O}+\frac{1}{2} \mathrm{O}_{2}+2 e \text { no eletrodo positivo }
$$




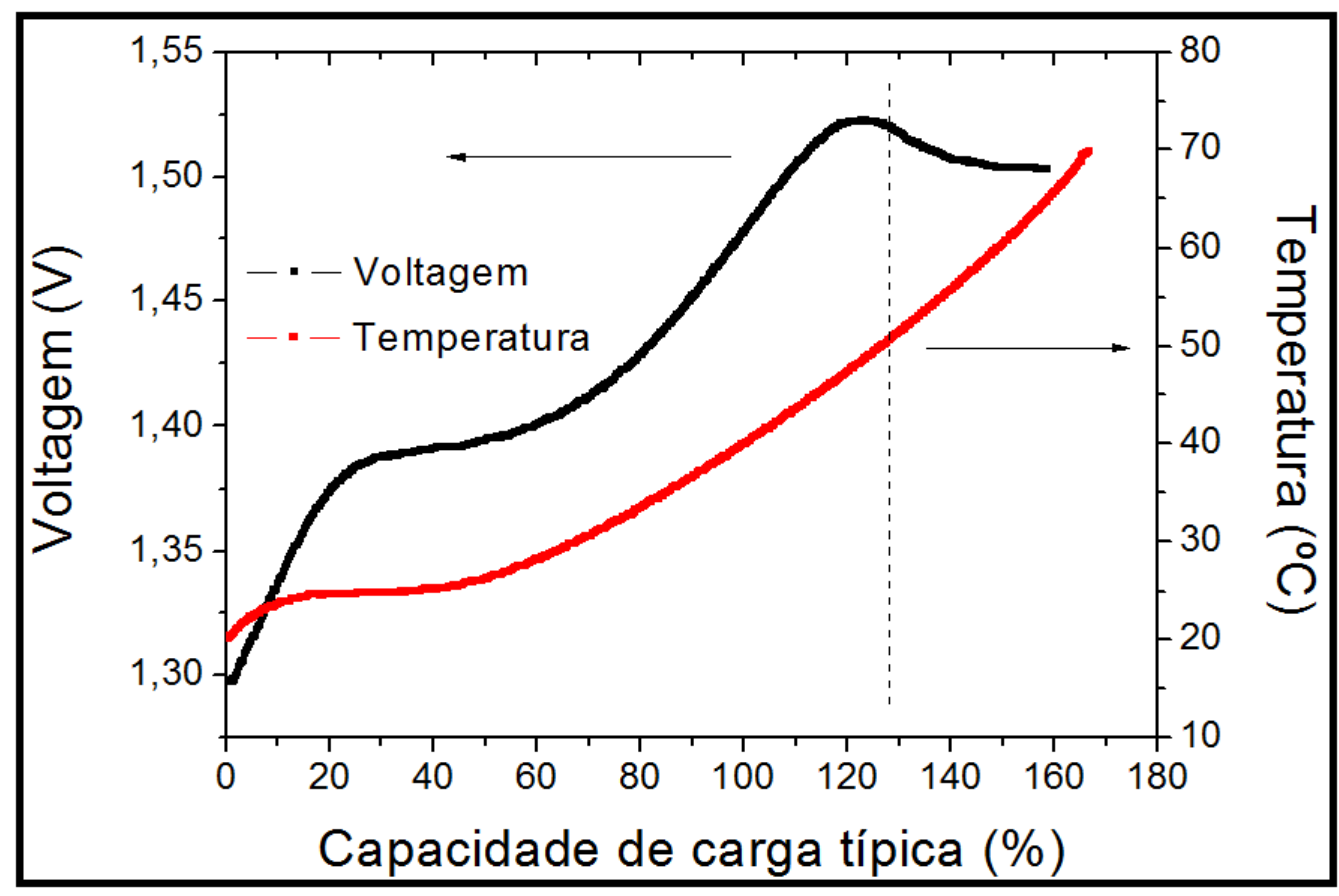

Fig. 2 - Voltagem e temperatura típicas de uma bateria de NiMH em função da carga inserida em percentagem da sua capacidade de carga. Fonte: Adaptação de gráficos separadamente divulgados em Linden e Reddy (2002).

$$
4 \mathrm{MH}+\mathrm{O}_{2} \rightarrow 4 \mathrm{M}+2 \mathrm{H}_{2} \mathrm{O} \text { no eletrodo negativo }
$$

Além da diferença de potencial (voltagem), a energia que a pilha fornece depende também da sua capacidade de carga, que para este tipo de pilha, nada mais é do que a quantidade de íons $\left(\mathrm{H}^{+}\right)$e elétrons que podem ser inseridos e retirados reversivelmente das estruturas dos materiais ativos. Por isso, a análise de uma pilha ou bateria recarregável independente do modelo ou tipo, mas passa pela determinação desta capacidade, já que com o tempo, independentemente do uso ou não da pilha, ocorre uma diminuição na quantidade de carga que ela pode fornecer reversivelmente. O problema mais comumente conhecido para este tipo de pilha, de $\mathrm{NiMH}$, é o efeito memória, que diminui a performance da pilha quando esta não é descarregada completamente, causando uma redução na capacidade de carga. O nome é dado devido à pi1ha/bateria se "lembrar" de sempre não ser descarregada por completo, fornecendo assim uma capacidade de carga menor do que deveria. No entanto, este efeito pode ser eliminado ao se realizar uma descarga completa, que em potenciais significa valores abaixo de $1,1 \mathrm{~V}$, considerando que o componente ainda não tenha sofrido um significativo desgaste por uso (ibid.). Com isso, uma bateria real passa a não fornecer toda capacidade informada pelo fabricante, mas sim uma percentagem dela. A este percentual é dado o nome de, do inglês, state of health, ou simplesmente SOH. Assim, uma pilha que tenha o SOH próximo de $100 \%$ significa que fornece praticamente toda capacidade indicada pelo fabricante, já valores menores indicam que houve uma perca de capacidade. $\mathrm{O} \mathrm{SOH}$ pode ser determinado pela quantidade de carga fornecida pela 
pilha no processo de descarga (corrente aplicada multiplicada pelo tempo gasto) dividido pela capacidade de carga fornecida pelo fabricante, (capacidade nominal - $C_{N}$ ). Genericamente, o $\mathrm{SOH}$ pode ser assim expresso:

$$
S O H=\frac{100 \%}{C_{N}} \cdot \int i(t) \cdot d t
$$

Desta forma, a partir do analisador desenvolvido neste trabalho, é possível classificar pilhas e/ou baterias de NiMH quanto ao seu estado de saúde, além de possibilitar ao professor melhor explorar os conceitos físico-químicos envolvidos a partir das informações detalhadas graficamente.

Outros tipos de pilha/bateria, como as de NiCd ou de íons de lítio, também podem ser utilizadas neste analisador, porém são necessárias algumas adaptações, já que este analisador contempla a teoria envolvida nas pilha de NiMH. Como o processo de carga/descarga nas pilhas de NiCd é semelhante às de NiMH, a única adaptação necessária seria a diminuição na temperatura que limita o processo de carregamento, pois a reação exotérmica neste tipo de material é menor do que a de NiMH. Já para as pilhas/baterias de íon lítio é necessário um controle também na diferença de potencial (tensão) do dispositivo, sendo que, neste tipo de material, caso o carregamento seja realizado apenas por aplicação de corrente elétrica, sua tensão aumenta excessivamente causando uma autodegradação do dispositivo ao ultrapassar os 4,2 V.

\section{Protótipo analisador utilizando a placa Arduino}

Conforme apresentado na Seção 2, a análise de pilhas e de baterias envolve processos sequenciais de carga e de descarga. Como forma de atender os requisitos para análise, o protótipo desenvolvido utiliza uma placa Arduino $\mathrm{Nano}^{\circledR}{ }^{\circledR}$ interligado com o ambiente de computação técnica Matlab® (CHAPMAN, 2003). Esta abordagem possibilita utilizar a placa Arduino como um hardware acionador e aquisitor de dados analógicos e digitais do sistema físico real (SFR) enquanto o ambiente Matlab ${ }^{\circledR}$ como o software controlador, visualizador e analisador dos dados dos processos de carga e descarga. Para isto, no Matlab ${ }^{\circledR}$ foi instalado o pacote de suporte ao Arduino (CAMPA, 2015), previamente gravado uma única vez e que interpreta comandos oriundos da porta serial virtual criada quando a placa está conectada a uma porta USB de um computador pessoal (PC). Assim, a placa Arduino funciona como um escravo dos comandos enviados pelo Matlab ${ }^{\circledR}$ por meio do pacote de suporte ao Arduino. A Fig. 3 apresenta em forma de diagrama de blocos a arquitetura do equipamento.

A Fig. 4 exibe o diagrama do circuito eletrônico utilizado que realiza a parte analógica do controle da carga e de monitoramento das variáveis de tensão, de corrente e de temperatura da pilha analisada. Na sequência é realizada uma breve descrição de cada etapa do circuito. 


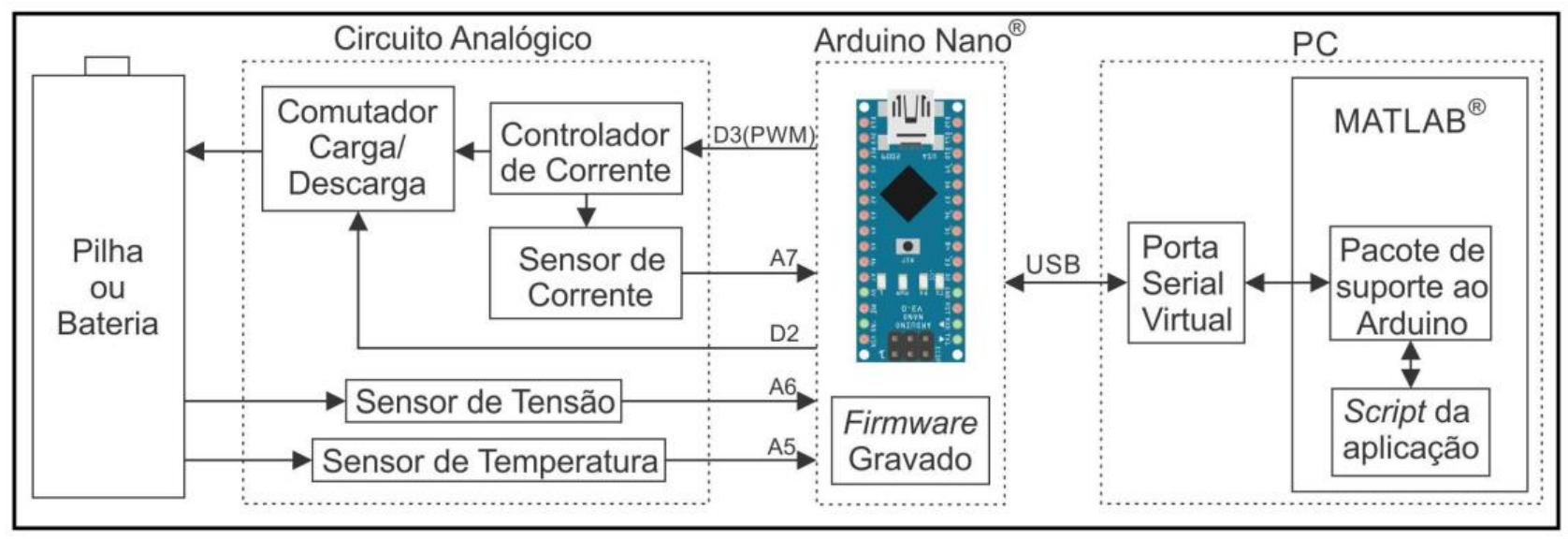

Fig. 3 -Diagrama de blocos da arquitetura do analisador. Fonte: autores.

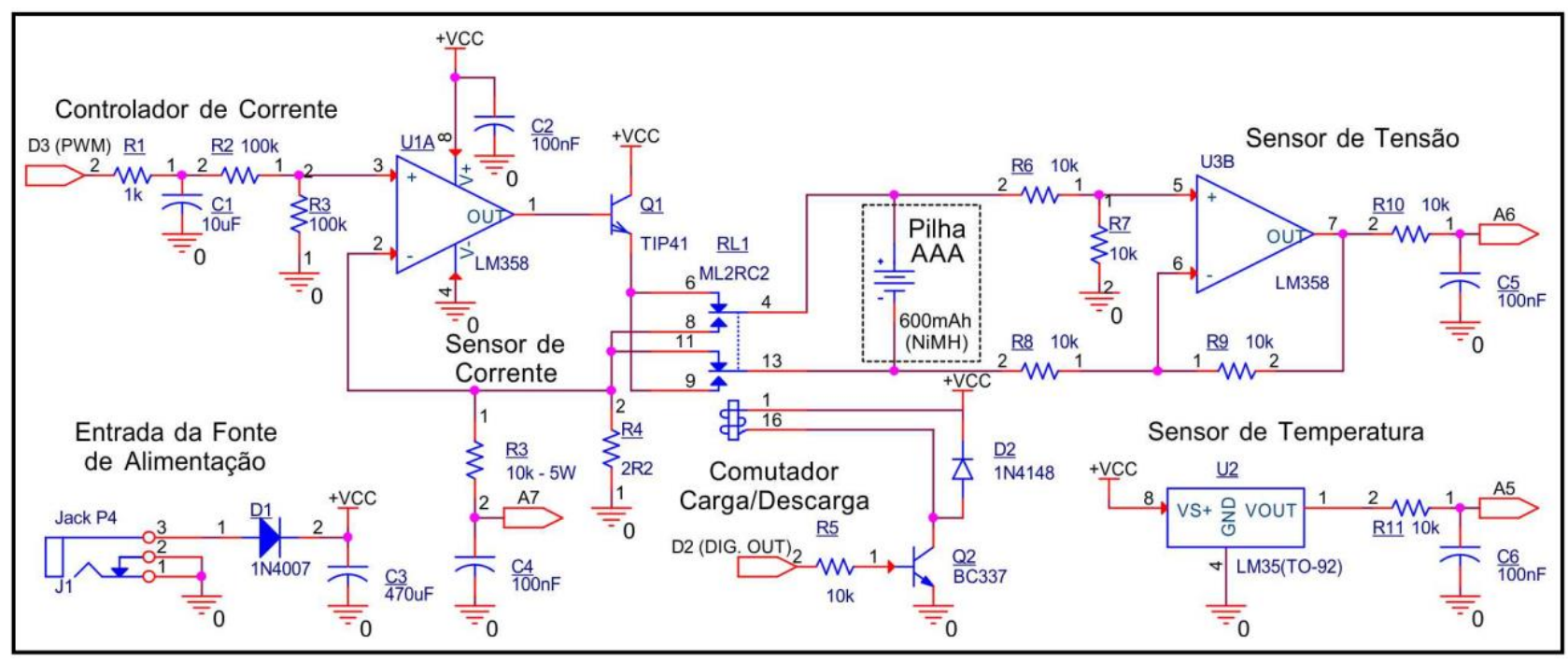

Fig. 4 - Diagrama eletrônico do circuito analógico. Fonte: autores.

A corrente de carga é definida inicialmente em um valor entre 50 à $1000 \mathrm{~mA}$. Este valor é convertido para outro valor entre 0 a 255 ( 8 bits) que serve de parâmetro do ciclo ativo do sinal de PWM (do inglês, modulação por largura de pulso) a ser gerado no pino D3 do Arduino. Para isto, o script Matlab envia um comando serial com este parâmetro para o firmware interpretador do Arduino. No circuito analógico, o resistor R1 e o capacitor $\mathrm{C} 1$ atuam como um filtro tornando o sinal PWM em um sinal de tensão fixa e contínua proporcional à corrente desejada. Este sinal de tensão serve de referência para o Circuito Amplificador Operacional (AmPop) do Circuito Integrado (CI) U1A, que faz o controle de corrente, comparando essa tensão de referência com a queda de tensão no resistor shunt R4. O sensor de corrente extrai essa queda de tensão e obtém a corrente indiretamente por meio da lei de Ohm. A Fig. 5 exibe uma foto da montagem em matriz de contatos do hardware analisador.

A seleção do processo é feita por meio do relê RL1 que, enquanto desacionado, permanece em processo de carga, permitindo que a corrente elétrica entre pelo polo positivo da 
pilha. Se ativado pelo script de controle por meio do pino de saída D2 do Arduino, ele inverte a polaridade da pilha passando a descarrega-la. Por sua vez, o sensor de tensão utiliza o outro AmPop do CI U3B como amplificador subtrator de tensão. Assim, ele apresenta, após o filtro RC (resistor R10 e capacitor C5), o sinal de tensão filtrado de ruídos para a entrada analógica A6 do Arduino. Essa tensão é a ddp (diferença de potencial) entre os terminais da pilha. Já o sensor de temperatura, acoplado termicamente à pilha, é composto pelo CI sensor LM35 e o outro filtro RC (resistor R11 e capacitor C6), que fornece na entrada analógica A5 uma tensão proporcional à temperatura $\mathrm{T}$ da pilha. Segundo o fabricante, (TEXAS INSTRUMENTS, 2013), a saída de tensão é de:

$$
V_{\text {Temperatura }}=0 \mathrm{mV}+10,0 \mathrm{mV} \cdot \mathrm{T} \text {. }
$$

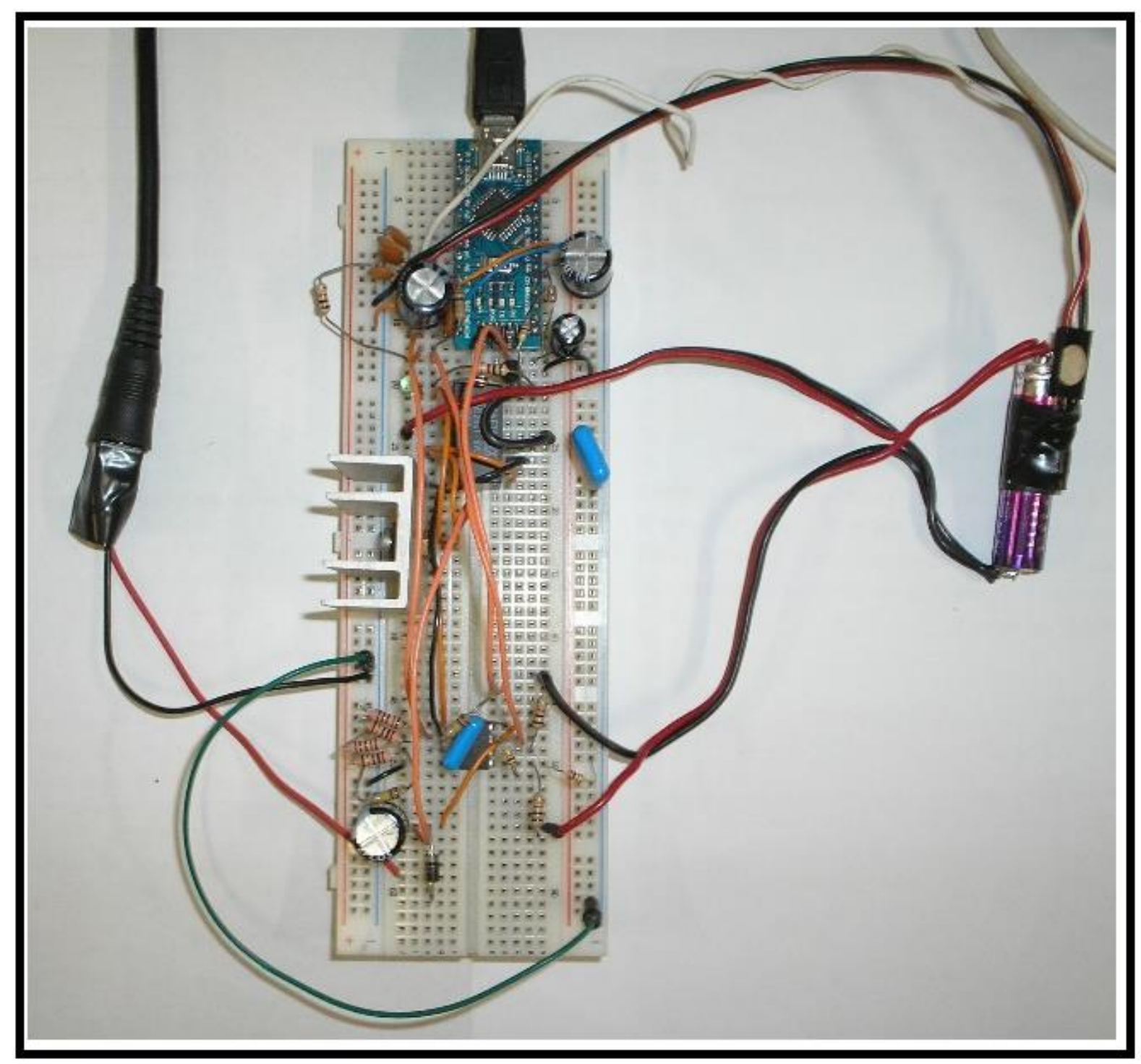

Fig. 5 - Foto do instrumento analisador. Fonte: autores. 


\section{Procedimento experimental}

Para exemplificar a utilização do dispositivo aqui desenvolvido, objetivou-se analisar o SOH de 3 pilhas de diferentes marcas e capacidades de carga, mas sempre prevalecendo as características de dimensões (AAA) e tipo (NiMH).

A determinação do $\mathrm{SOH}$ das pilhas foi realizada seguindo o protocolo $\mathrm{CC}$ (Corrente Contínua), sempre com uma corrente aplicada igual à capacidade nominal da pilha (isto é, 1C). Por exemplo, foram aplicadas correntes de $600 \mathrm{~mA}$ tanto no carregamento como no descarregamento da pilha de $600 \mathrm{mAh}$. O procedimento completo aplicado nas pilhas compõe-se de 3 partes: inicialmente, a pilha é descarregada até o potencial de 1,0 V. Depois, carrega-se a pilha até que ela atinja a temperatura de $50^{\circ} \mathrm{C}$. Por fim, a pilha é descarregada novamente até $1,0 \mathrm{~V}$, fornecendo assim os dados para o cálculo da sua capacidade de carga. Na parte inicial tem-se a intenção de equiparar as pilhas num mesmo estado de carga para poderem ser comparadas, além de reduzir ou eliminar o efeito memória. Já na segunda parte, a temperatura de $50{ }^{\circ} \mathrm{C}$ no carregamento é admitida com base na Fig. 1, pois, como nela é indicado, esta temperatura surge logo após o "pico" no qual a pilha ou bateria encontra-se carregada (sendo a carga inserida de aproximadamente $130 \%$ da sua capacidade típica). A terceira parte, descarregamento da bateria, é a etapa que fornece os dados para calcular o $\mathrm{SOH}$ da pilha.

O sensor LM35 foi utilizado para medir a temperatura da pilha e que nela permaneceu fixado com fita isolante. Para auxiliar a evitar a perda de calor para o ambiente devido ao aquecimento das pilhas, elas ainda foram envoltas por uma flanela, simplesmente funcional à situação como "isolante térmico".

Os dados fornecidos pelo instrumento são os valores de tempo transcorrido, corrente, voltagem e temperatura da pilha, obtidos nos processos de carga e descarga. Tais valores foram plotados em software de gráficos para análise e determinação do "estado de saúde" (SOH) das pilhas examinadas. A Tabela 1 apresenta uma orientação aos resultados de $\mathrm{SOH}$, conforme critérios divulgados em URBANO et al. (2009), ainda que cotidianamente a determinação do quão eficiente ou aceitável seja a resposta de uma pilha acabe por conta do usuário, ao julgar que um dispositivo suportado por determinada pilha está funcionando adequadamente ou não.

Tabela 1 - Critério de classificação de pilhas por SOH.

\begin{tabular}{|l|l|}
\hline SOH & Classificação \\
\hline SOH $\geq 85 \%$ & Excelente \\
\hline $85 \%>\mathrm{SOH} \geq 70 \%$ & Boa \\
\hline $\mathrm{SOH}<70 \%$ & Ruim \\
\hline
\end{tabular}

Fonte: Urbano et al. (2009). 
Visando uma validação dos resultados obtidos com o analisador desenvolvido neste trabalho, o mesmo processo de análise foi aplicado nas pilhas estudadas por um equipamento comercial utilizado em estudos e análises de pilhas e baterias, um potenciostato/galvanostado da marca Arbin Instruments, modelo MSTAT 8000/BT2000, sendo realizadas todas as medições num canal com fundo de escala de $1 \mathrm{~A}$.

\section{Resultados e análises}

A partir da metodologia relatada anteriormente, os resultados alcançados com as pilhas são expostos nas Fig. 6 e 7. Na Fig. 6, como forma de ilustrar típicos gráficos de dados coletados na plenitude do processo, exemplificam-se os resultados obtidos com a pilha de $900 \mathrm{mAh}$.

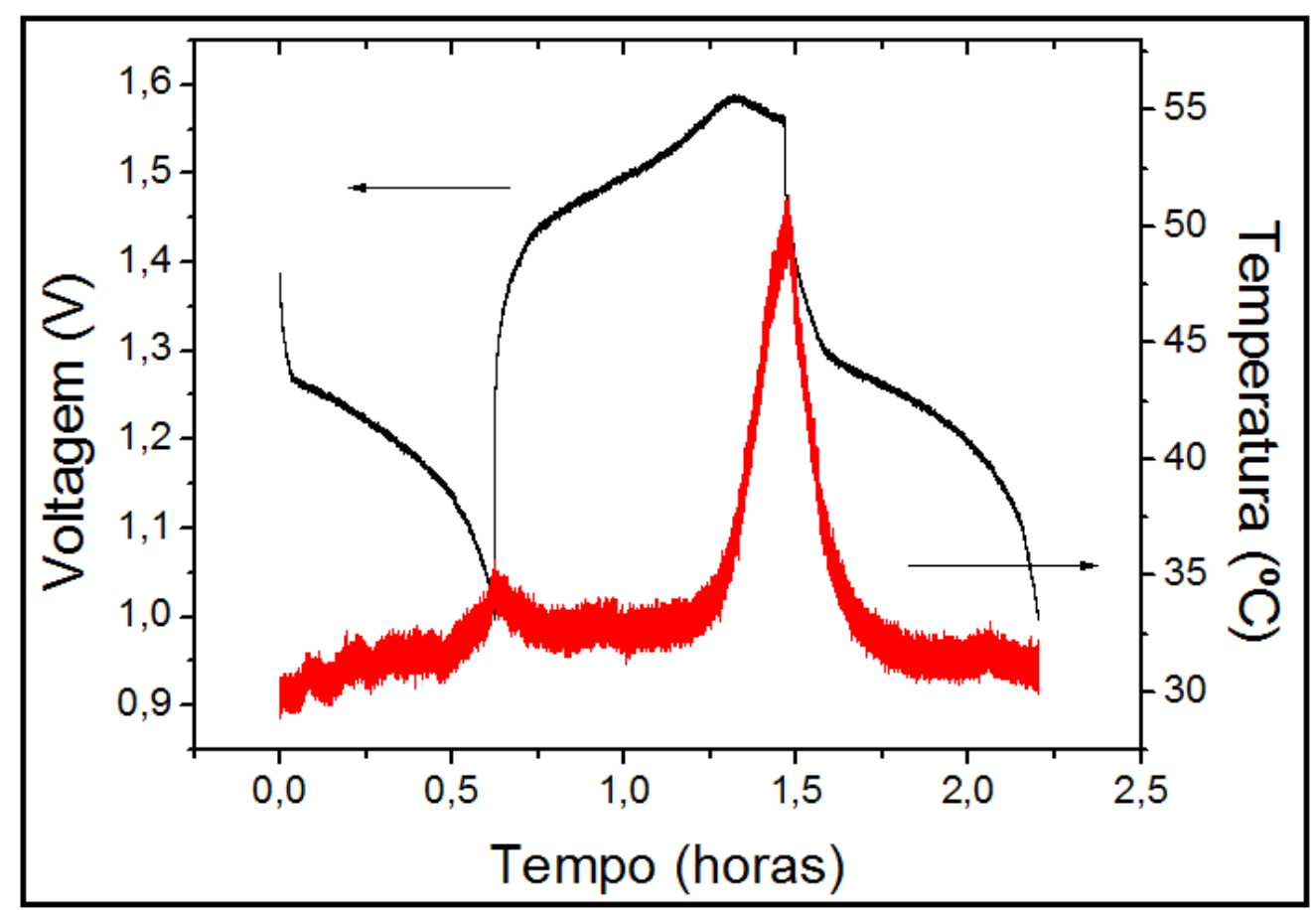

Fig. 6 - Voltagem e temperatura em função do tempo obtidos da pilha de $900 \mathrm{mAh}$ a partir do dispositivo desenvolvido neste trabalho. Fonte: autores.

Possibilita-se, pelos gráficos da Fig. 6, identificar que a amostra é de uma pilha de $\mathrm{NiMH}$, em que facilmente se caracterizam semelhanças com as curvas da Fig. 1, identificação essa que se repetiu às demais pilhas. Cabe dizer que a importância dessa observação se dá no fato de algumas pilhas vendidas no comércio poderem apresentar informações equivocadas (falsas) em seus invólucros (Urbano et al., 2010). Já com relação às determinações de SOH, a partir da equação 4, foram encontrados os seguintes resultados, indicados na Tabela 2. 
Tabela 2 - Valores de capacidade de carga (C) e SOH obtidos com o analisador desenvolvido neste trabalho e com o equipamento de validação.

\begin{tabular}{|c|c|c|c|c|}
\hline \multirow{2}{*}{ AMOSTRAS } & \multicolumn{2}{|c|}{ ARDUINO } & \multicolumn{2}{c|}{ POTENCIOSTATO/GALVANOSTATO } \\
\cline { 2 - 5 } & $\mathbf{C}$ & SOH & $\mathbf{C}$ & SOH \\
\cline { 2 - 5 } & mAh & $\boldsymbol{\%}$ & mAh & \% \\
\hline P900 & 628,73 & 70 & 613,98 & 68 \\
\hline P700 & 601,80 & 86 & 587,77 & 84 \\
\hline P600 & 384,83 & 64 & 352,65 & 59 \\
\hline
\end{tabular}

Fonte: autores.

Com referência aos critérios da Tabela 1, verifica-se que a pilha de $700 \mathrm{mAh}$ (P700) está em "excelentes" condições de fornecimento de carga. A pilha de $900 \mathrm{mAh}$ (P900), apesar da perda de capacidade de carga, ainda é uma "boa" bateria. Já a pilha de 600 mAh (P600) pode-se aconselhar a substituição, pois segundo URBANO et al. (2009) esta é uma bateria ruim, ou seja, com substancial perda de eficiência na energia que esta fornece. Porém, como já dito anteriormente, a decisão ou não da substituição da pilha cabe ao usuário do dispositivo que comporta a pilha.

Quanto à validação dos resultados obtidos com o analisador desenvolvido neste trabalho, verifica-se que os valores foram muito próximos aos do equipamento comercial, diferenciados com cerca de apenas $2 \%$ (Tabela 2), o que certifica o dispositivo desenvolvido e apoia as análises realizadas. A respeito dessa aparente tendência dos valores de capacidade de carga surgirem menores para as medidas com o equipamento comercial, ela está em função dos experimentos terem sido primeiro realizados no mesmo. Dessa forma, como as descargas são realizadas até $1,0 \mathrm{~V}$, existe uma redução no efeito memória durante as medidas nesse equipamento, devendo as próximas medidas serem ligeiramente maiores, ou no mínimo iguais às dele, sem considerar a diferença entre equipamentos.

A perda de capacidade de carga nestas pilha pode ocorrer por vários fatores, como carregamentos inadequados, exposição à altas temperatura, sobrecargas, além do desgaste natural, sendo que durante os processos de carregamento e descarregamento de um pilha de $\mathrm{NiMH}$ ocorrem transições de fase devido à inserção e retirada de hidrogênio, alterando o seu volume e causando tensões no interior do dispositivo, assim como um aumento na resistência interna (FLORIANO, 2009, p. 131; LINDEN; REDDY, 2002, BODY et al., 1966).

Além do processo de carregamento/descarregamento de uma pilha, outro conceito físico-químico que pode ser explorado com este analisador está nas reações exotérmicas que ocorrem a partir dos dados de temperatura obtidos no processo de carregamento (Fig. 7). Com eles é possível observar reações que liberam maior ou menor energia, chegando até à conclusões semelhantes às obtidas com o SOH. Ao se observar a Fig. 7 pode-se dividir o carregamento em 
duas partes, uma onde não há, ou há pouca variação na temperatura e outra em que a temperatura varia consideravelmente. Isso ocorre porque estas regiões são "governadas" por reações diferentes. Na região com pouca variação da temperatura, onde a reação principal é a de inserção/retirada de hidrogênio (reação 1 carregando), verifica-se que o maior carregamento, em percentagem, ocorre na pilha de $700 \mathrm{mAh}$, seguido da pilha de $900 \mathrm{mAh}$, e com o menor na pilha de $600 \mathrm{mAh}$. Na região de maior variação da temperatura a reação principal é a de recombinação do oxigênio (reações 2 e 3 ) e ela não armazena energia química de forma a ser reutilizada. Como a pilha não pode fornecer mais energia do que havia armazenado, o professor pode elencar as pilhas de forma a indicar a que fornecerá a maior ou menor porcentagem da capacidade de carga.

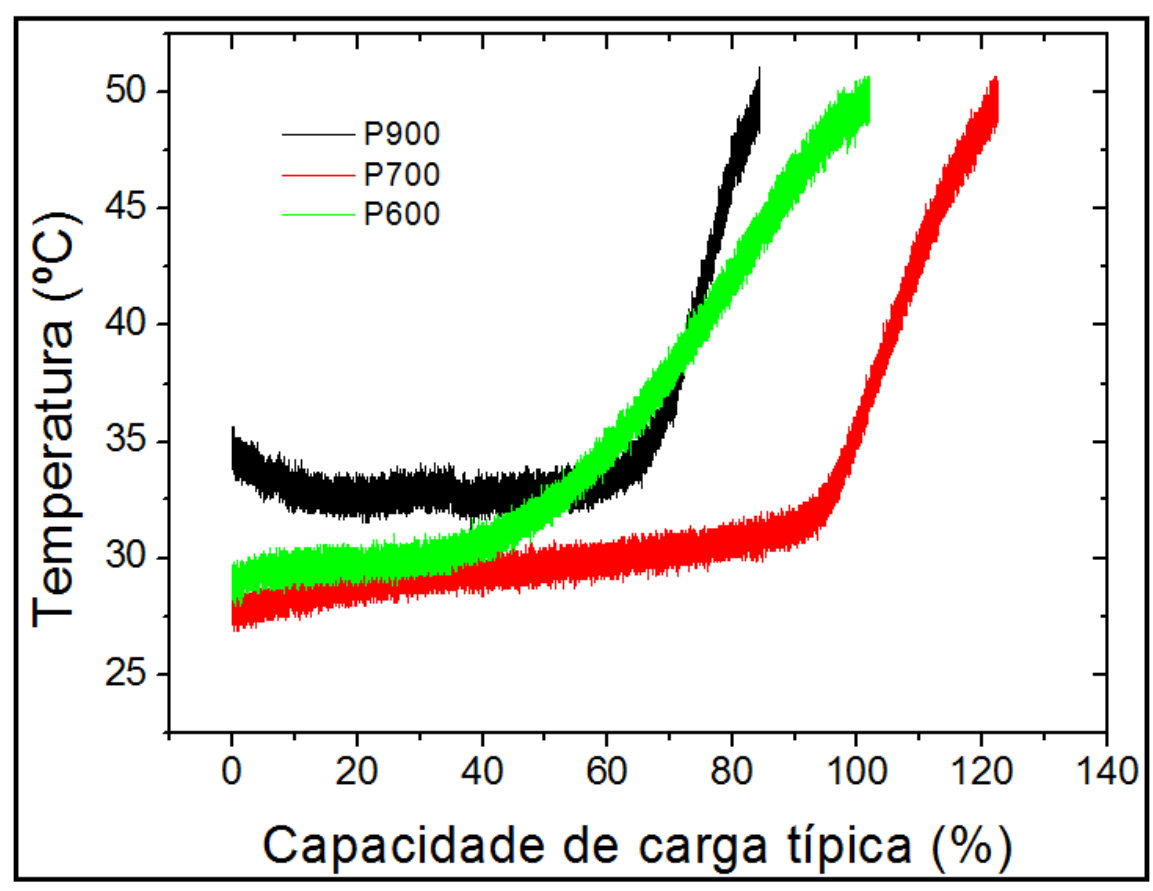

Fig. 7 - Temperatura das pilhas estudadas em função da percentagem da capacidade de carga inserida. Fonte: autores.

\section{Considerações finais}

Este trabalho objetivou a realização de duas contribuições: fornecer uma simples e econômica proposta de montagem de um carregador e analisador de pilhas e baterias, que se equipara em qualidade e quantidade de informações aos dos mais sofisticados modelos residenciais comercializados, cujo detalhamento de informações torna-se proveitoso educacionalmente; e, por consequência, proporcionar uma análise exemplar de dados dos resultados encontrados que venha subsidiar aquele educador interessado na presente proposta. Enfim, com uma abordagem educacional elucidativa dos princípios da elaboração de um equipamento de análise 
de pilhas e baterias, espera-se beneficiar o ambiente escolar com uma alternativa forma interdisciplinar de aplicar conceitos físicos, químicos e matemáticos por meio de tal inserção tecnológica.

\section{Referências}

ARBIN INSTRUMENTS - MODELO MSTAT 8000/BT2000. ARBIN INSTRUMENTS (Battery, Capacitor, and Fuel Cell Test Equipament). Disponível em: <http://www.arbin.com/index.php/products/battery\#/bt-2000>. Acesso em: 12 abr. 2016.

BODE, H.; DEHMELT, K.; WITTE; J. Electrochem. Acta, v. 11, p. 1079, 1966.

CAMPA, G. Legacy Matlab and Simulink Support for Arduino. Disponível em: <http://www.mathworks.com/matlabcentral/fileexchange/32374-legacy-matlab-and-simulinksupport-for-arduino>. Acesso em: 12 abr. 2016.

CAVAlCANTE, M. A.; RODRIGUES, T. T. T.; BUENO, D. A. Controle Remoto: observando códigos com o Arduino (parte 2 de 2). Caderno Brasileiro de Ensino de Física, v. 31, n. 3, p. 614-641, 2014.

CAVAlCANTE, M. A.; TAVAlARO, C. R. C.; MOLISANI, E. Física com Arduino para iniciantes. Revista Brasileira de Ensino de Física, v. 33, n. 4, p. 4503-4509, 2011.

CHAPMAN, S. J. Programação em MATLAB para engenheiros. São Paulo: Pioneira Thomson Learning (2003). Disponível em: <http://docslide.com.br/documents/programacao-emmatlab-para-engenheiros-stephen-j-chapmanpdf.html>. Acesso em: 12 abr. 2016.

FLORIANO, R. Caracterização de baterias de Níquel hidreto metálico (Ni-HM) e de íonlítio de telefone celular. 2009. Dissertação (Mestrado) - Departamento de Física, Universidade Estadual de Londrina.

LINDEN, D; REDDY, T. B. Handbook of Batteries. 3. ed. New York: McGraw-Hill, 2002.

ROCHA, F. S.; MARRANGHELLO, G. F.; LUCCHESE, M. M. Acelerômetro eletrônico e a placa Arduino para ensino de Física em tempo real. Caderno Brasileiro de Ensino de Física, v. 31, n. 1, p. 98-123, abr. 2014.

SKYRC SK-100059-01 NC2500. Carregador e analisador de bateria com Bluetooth. Disponível em: <http://www.dx.com/pt/p/skyrc-sk-100059-01-nc2500-4-x-aa-aaa-nimh-batterycharger-analyzer-w-bluetooth-black-red-241215\#.Vw4-LPkrJdg>. Acesso em: 11 abr. 2016.

ROSA, C. T. W.; TRENTIN, M. A.; ROSA, A. B.; GIACONELLI, A. C. Experimento de condução térmica com e sem uso de sensores e Arduino. Caderno Brasileiro de Ensino de Física, v. 33, n. 1, p. 292-305, abr. 2016. 
SILVA, O. H. M.; MATHIAS, L. C. Possíveis aplicações do Arduino em Equipamentos Interativos de ambientes planejados à Educação não formal: uma proposta equivalente nas escolas. RENOTE (Revista Novas Tecnologias na Educação), v. 13, n. 1, julho 2015.

SOUZA, A. R. et al. A placa Arduino: uma opção de baixo custo para experiências de Física assistidas pelo PC. Revista Brasileira de Ensino de Física, v. 33, n. 1, p. 1702, 2011.

TEXAS INSTRUMENTS. LM35 Precision Centigrade Temperature Sensors. (2013). Disponível em: 〈http://www.ti.com/lit/ds/symlink/lm35.pdf〉. Acesso em: 12 abr. 2016.

URBANO, A. et al. Método rápido de análise do estado de saúde ( $\mathrm{SOH}$ ) de baterias de íon lítio de telefones descartados empregando os conceitos da técnica de titulação galvanostática intermitente (GITT). Semina. Ciências Exatas e Tecnológicas, v. 30, p. 137-144, 2009.

URBANO, A. et al. O. Estudo do desempenho elétrico e da composição química de baterias de Ni-HM original e falsificada. Semina. Ciências Exatas e Tecnológicas (Online), v. 31, p. 181$189,2010$. 